\title{
Microstructural Development in As Built and Heat Treated IN625 Component Additively Manufactured by Laser Powder Bed Fusion
}

\author{
Holden Hyer ${ }^{1} \cdot$ Ryan Newell $^{2} \cdot$ Dan Matejczyk $^{3} \cdot$ Sinsar Hsie $^{2} \cdot$ Mason Anthony $^{2}$ • \\ Le Zhou ${ }^{1}$ - Cathy Kammerer ${ }^{2}$ Y Yongho Sohn ${ }^{1}$
}

Submitted: 27 July 2020/in revised form: 10 November 2020/ Accepted: 17 November 2020/Published online: 3 January 2021 (C) ASM International 2021

\begin{abstract}
The RL10 engine program is exploring the use of IN625 Ni-base superalloy components that are additively manufactured using laser powder bed fusion (LPBF). IN625 alloy powders are commercially available for LPBF to produce dense, complex parts/components. In this study, IN625 components, with both simple and complex geometries with overhangs, were manufactured via LPBF, and subjected to a heat-treatment consisting of a stress relief, hot isostatic pressing (HIP), and a solution anneal. The microstructure was examined with optical, scanning electron, and transmission electron microscopy. Changes in phase constituents and microstructure were documented as a function of heat treatment and component geometry (i.e., bulk section built on support structure versus thin, overhang section built on top of the previous powder bed). The as-built microstructural features included large columnar grains, a sub-grain cellular-solidification structure, approximately $\sim 1 \mu \mathrm{m}$ in diameter, and solute enriched cell boundaries decorated with $\mathrm{A}_{2} \mathrm{~B}$ Laves phases. After heat treatment, the bulk section consisted of recrystallized equiaxed grains with annealing twins, and the sub-grain cellular-solidification structure was found to be completely dissolved. However, in the thin, overhang section, the subgrain cellular-solidification structure persisted within columnar grain structure, which exhibited no
\end{abstract}

Holden Hyer

hhyer@knights.ucf.edu

Yongho Sohn

yongho.sohn@ucf.edu

1 Department of Materials Science and Engineering, University of Central Florida, Orlando, FL

2 Aerojet Rocketdyne, West Palm Beach, FL

3 Aerojet Rocketdyne, Canoga Park, CA recrystallization. An alternate HIP cycle with a higher temperature was employed to produce desired microstructure (i.e., recrystallized grains without sub-grain cells and Laves phases) in components with geometrical complexity for successful testing of RL10 engine.

Keywords additive manufacturing - heat treatment Inconel · transmission electron microscopy . microstructural characterization

\section{Introduction}

The RL10 engine program is exploring the use of Inconel 625 (IN625) Ni-base superalloy components that are additively manufactured using laser powder bed fusion. Alloyed primarily with $\mathrm{Mo}, \mathrm{Cr}, \mathrm{Fe}$, and $\mathrm{Nb}$, IN625 is a solid solution strengthened Ni-based superalloy with high strength, high creep resistance, exceptional corrosion resistance, and good weldability. ${ }^{[1-3]}$ IN625 also includes additions of $\mathrm{Ti}$ and $\mathrm{Al}$ for grain refinement purposes. ${ }^{[1,2]}$ Even though IN625 was designed to be a single phase (face-centered-cubic, FCC $\gamma$-phase), local segregation of $\mathrm{Ti}, \mathrm{Al}$, and $\mathrm{Nb}$ can lead to precipitation of Laves phases $\left(\mathrm{A}_{2} \mathrm{~B}\right.$ or $\left.\mathrm{AB}_{2}\right)$ and $\mathrm{Ni}_{3} \mathrm{Nb}$ phases. ${ }^{[1,2,4]}$ The $\mathrm{Ni}_{3} \mathrm{Nb}$ can precipitate as the strengthening body-centered tetragonal $\gamma$ "-phase or the undesirable orthorhombic $\delta$-phase. ${ }^{[1,2]}$ Both the Laves and $\delta$-phase have shown to decrease the strength and fatigue life of IN625. ${ }^{[1,2,5-7]}$ Therefore, proper processing and heat treatment is critical to produce the intended solid solution $\gamma$-phase in IN625. ${ }^{[1,2]}$

Additive manufacturing (AM) is an emerging technology that has demonstrated the ability to produce complex geometries to full density and net shape ${ }^{[8-10]}$ Increasing in 
popularity, laser powder bed fusion (LPBF) is a versatile AM technique in which a powder bed is selectively melted by a laser source to build a component in a layer by layer process. ${ }^{[9-11]}$ Despite significant success and potential, not all commercial alloys have shown to behave well during LPBF processing. ${ }^{[10,12]}$ For example, many commercial alloys such as high strength Al-alloy AA7075 ${ }^{[12]}$ and high strength Ni-based superalloy CM247 [13, 14] currently cannot be processed with LPBF because of solidification cracking and/or formation of excessive porosity. In accordance with its high weldability, IN625 is among the few Ni-based superalloys, along with IN718 ${ }^{[15,16]}$ and IN939, ${ }^{[17]}$ that have shown consistently excellent "buildability" for LPBF. ${ }^{[7,18-20]}$

Cooling rates in LPBF have been estimated to be on the orders of $10^{5}-10^{7} \mathrm{~K} / \mathrm{s},{ }^{[7,}{ }^{21]}$ which are considerably higher than that of conventional large-scale casting process with cooling rates on the orders of $10^{1}-10^{3} \mathrm{~K} / \mathrm{s}$. During solidification of IN625 in conventional casting, the final liquid segregated to the interdendritic boundaries is enriched primarily with $\mathrm{Nb}$, and possibly some Ta and Mo. ${ }^{[1,2,4]}$ The $\mathrm{Nb}$ enriched liquid can lead to the formation of $\mathrm{NbC}$ carbides, Laves phases, and $\mathrm{Ni}_{3} \mathrm{Nb}$ (e.g., $\delta$-phase). ${ }^{[1,2,4]}$ Despite the considerably higher cooling rates in LPBF, many of these secondary phases can be observed in as-built LPBF IN625 microstructure. ${ }^{[7,18,20]}$ Moreover, a higher degree of $\mathrm{Nb}$ and Mo segregation (i.e., higher concentration) has been observed along the sub-grain, cellular-solidification structure. ${ }^{[7,18,20]}$ Similar segregation has been also observed in IN718 and IN939 Ni-based superalloys produced by LPBF. ${ }^{[15,17]}$

Due to the high degree and resolution of segregation observed in LPBF IN625, post heat treatment is necessary in order to produce the intended solid solution. Repeated melting and rapid solidification characterized by high cooling rate in LPBF has been shown to cause high residual stress, large dislocation densities, and high angle grain boundaries. ${ }^{[7,18,22]}$ Therefore, a multi-step heat treatment using various temperatures for stress relief and solution anneal has been examined. A typical stress relief for cast IN625 is performed between 650 and $870{ }^{\circ} \mathrm{C}$ for $1-2 \mathrm{~h}^{[23]}$ However, the application of this standard stress relief treatment on LPBF IN625 has been shown to incur pre-

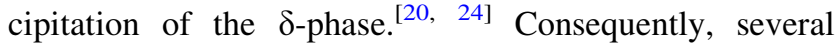
studies by the National Institute of Standards and Technology (NIST, Gaithersburgh, MD, USA) have reported considerable details on proper heat treatment for LPBF IN625, including modified Time-Temperature-Transformation (TTT) diagrams. ${ }^{[7,20,24,25]}$ Their findings have shown that conventional heat treatment utilized in industry for conventionally manufactured IN625 cannot be employed for LPBF IN625 without the consequence of unwanted microstructures, e.g., formation of the $\delta$-phase.
Therefore, optimizing heat treatments between 600 and $900{ }^{\circ} \mathrm{C}$ in order to avoid the Laves and $\delta$-phase has been the focus of these studies, which recommended the use of both lower temperatures and reduced time.

Marchese et al. ${ }^{[26]}$ and Kreitcberg et al. ${ }^{[27]}$ have also investigated the microstructure and mechanical properties of LPBF IN625 before and after various heat treatments. ${ }^{[13,}{ }^{22,}{ }^{26-28]}$ Consistently, the as-built microstructure consisted of columnar grains with a sub-grain cellular-solidification structure. After a series of heat treatments consisting of stress-relief, possible hot isostatic pressing (HIP), and solution annealing, the columnar grains became more equiaxed and the sub-grain cellular-solidification structure was dissolved. Typically, studies such as these found in literature utilized LPBF to build IN625 samples with simple geometries (i.e., cubes, rectangles prisms, cylinders), which provides a simple heat conduction, directly down to the build-plate, throughout the LPBF process. Little has been examined in the way of processing complex geometries that can give rise to a variation in heat conduction (e.g., over-hang sections). Benchmark studies have been conducted by the NIST, ${ }^{[29-33]}$ focusing on thermal history and microstructural differences between areas of a part that are "bridged" with no supports that overhang on the previous powder bed, versus the supporting columns of the bridge, which are connected directly to the build plate. These studies have provided invaluable insight, with considerable discussion between the supported and un-supported areas.

In this study, a geometrically complex LPBF IN625 component to be employed in RL10 engine were characterized. Specifically, two different sections of the component, distinguished by their geometrical features, were examined. They are denoted as the (1) bulk and (2) thin sections throughout this paper. As depicted in Fig. 1, the

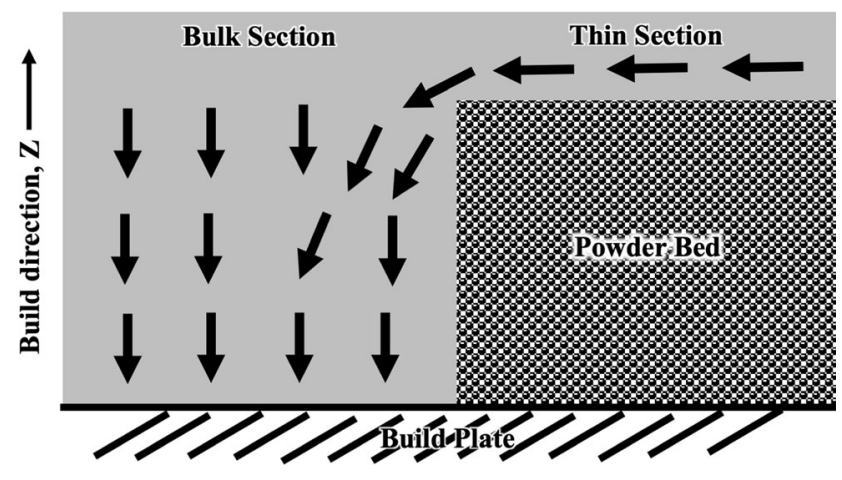

Fig. 1 A schematic representation of the sample geometry examined in this study, consisting of two sections denoted as the bulk and thin sections. The bulk section is welded directly to the build plate while the thin, over-hang section is connected to the bulk section, but sits on a powder bed, as there is no build plate support structure underneath. Arrows indicate direction of plausible heat conduction 
bulk section refers to a large volume of material, welded directly to the build plate, giving the bulk section a simple heat dissipation route as schematically illustrated in Fig. 1. Conversely, the thin section is representative of finer, more complex features, attached to the bulk section (e.g., overhang), usually sitting on a powder bed without build-plate support structure underneath. Therefore, the thin section must extract heat through the bulk section with a more complex heat dissipation route as schematically illustrated in Fig. 1. Since a high degree of solute segregation along the intercellular boundaries is observed in the as-built LPBF IN625 microstructure, the samples were subjected to a multi-stage heat treatment. Utilizing optical, scanning electron microscopy, and extensive transmission electron microscopy, this study examined the microstructural development between the bulk and thin sections before and after a multi-stage heat treatment. Findings demonstrated optimized heat treatment can alleviate the formation of solute segregation to prevent the formation of Laves and $\delta$ phase in both the bulk and thin sections of IN625 for high temperature application.

\section{Experimental Procedure}

\subsection{LPBF Processing}

Gas atomized IN625 powders were acquired from EOS with a mean particle size approximately $35 \mu \mathrm{m}$. The powder was then processed via LPBF on an EOS M400 under inert atmosphere, using parameters yielding a volumetric global energy density of $62 \mathrm{~J} / \mathrm{mm}^{3} \pm 10 \%$.

\subsection{Heat Treatment}

As-built components were first stress-relieved at temperature $\mathrm{T}_{1}$ for $2 \mathrm{~h}$ in an Ar atmosphere with rapid cooling. The components were bonded to the build plate for the stressrelieving heat treatment and were removed afterwards with a wire electrical discharge machine (EDM). Next, the stress-relieved components were hot isostatic pressed (HIP) at temperature $\mathrm{T}_{2}$ with a pressure of $100 \mathrm{MPa}$ using an $\mathrm{Ar}$ atmosphere. Note that $T_{1}>T_{2}$. A final solutionizing heat treatment was performed at $\mathrm{T}_{1}$ for $2 \mathrm{~h}$ with rapid cooling. Samples extracted from components subjected to the multistage heat treatment will be hereafter denoted as the Fully Heat Treated (FHT). Aerojet Rocketdyne has systematically investigated effects of time and temperature on microstructure of LPBF IN625 components, and the work presented in this study documents the resulting microstructure of the initially prescribed heat treatment, and an optimized alternative.

\subsection{Sample Preparation and Characterization}

As built and FHT IN625 samples, taken from both the bulk and thin sections, were sectioned appropriately to examine the microstructure across the build direction (e.g., XZ direction). All samples were first mounted in epoxy, and polished with $\mathrm{SiC}$ and diamond paste, to a final finish of $0.05 \mu \mathrm{m}$ using colloidal silica. Samples were then etched with a solution consisting of $60 \mathrm{~mL}$ hydrochloric acid, $6 \mathrm{~mL}$ of distilled water, and $6 \mathrm{~g}$ of cuprous chloride (anhydrous).

For cursory microstructural analysis, the samples were characterized utilizing optical microscopy (Nikon $^{\mathrm{TM}}$ Metaphot) and a Field-Emission Secondary Electron Microscope (FE-SEM, Zeiss ${ }^{\mathrm{TM}}$ Ultra-55) operating at $20 \mathrm{kV}$. Samples were typically characterized with backscatter atomic number contrast using FE-SEM. For detailed investigation into microstructure and constituent phases, samples were extensively examined by Transmission Electron Microscopy (TEM, FEI ${ }^{\mathrm{TM}}$ Tecnai F30 $300 \mathrm{kV}$ ). Focused ion beam (FIB, FEI ${ }^{\mathrm{TM}}$ TEM200) in situ lift-out (INLO) technique was employed to prepare several site-specific TEM-ready thin foils. TEM samples were characterized utilizing Bright Field (BF), Scanning TEM (STEM), High Angle Annular Dark Field (HAADF), Selected Area Electron Diffraction (SAED), High Resolution TEM (HRTEM), and standardless Energy Dispersive $\mathrm{x}$-ray Spectroscopy (EDXS by EDAX ${ }^{\mathrm{TM}}$ ) all performed at an accelerating voltage of $300 \mathrm{kV}$. Subsequent analytical TEM was carried out using Gatan ${ }^{\mathrm{TM}}$ Digital Micrograph software and $\mathrm{FEI}^{\mathrm{TM}}$ Tecnai Imaging and Analysis software.

\section{Results and Discussion}

\subsection{Microstructure of the As-Built IN625}

Figure 2 shows optical and backscatter electron micrographs of the as-built IN625 samples. Optical micrographs in Fig. 2(a) and (b) revealed multiple melt-pool structures from the consecutive melting-solidification during the LPBF for the thin and bulk sections, respectively. Long, columnar grains existing across several melt pools were observed in both sections by the etched contrast. Secondary phases could not be distinguished in the optical micrographs. Figure 2(c), (d), (e), and (f) present backscatter electron micrographs of the bulk and thin sections. Many sub-micron features that appear to be precipitates (or particles) and/or cells were observed, distributed uniformly throughout both samples. However, no discernable differences could be observed between the bulk and thin sections in the as-built IN625. For a better observation of sub-grain 
Fig. 2 Optical micrographs normal to the build direction for the (a) bulk and (b) thin walled sections of the as-built IN625. (c, d) Low and (e, f) high magnification backscatter electron micrographs for the (c, e) bulk and (d, f) thin sections
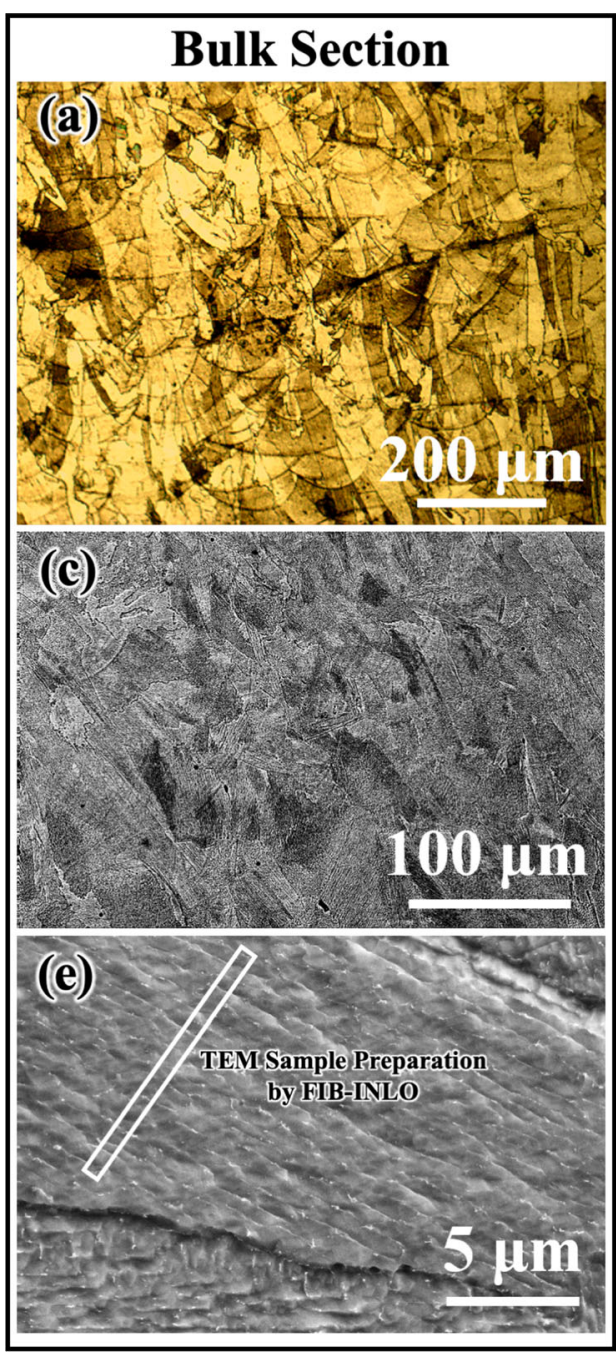
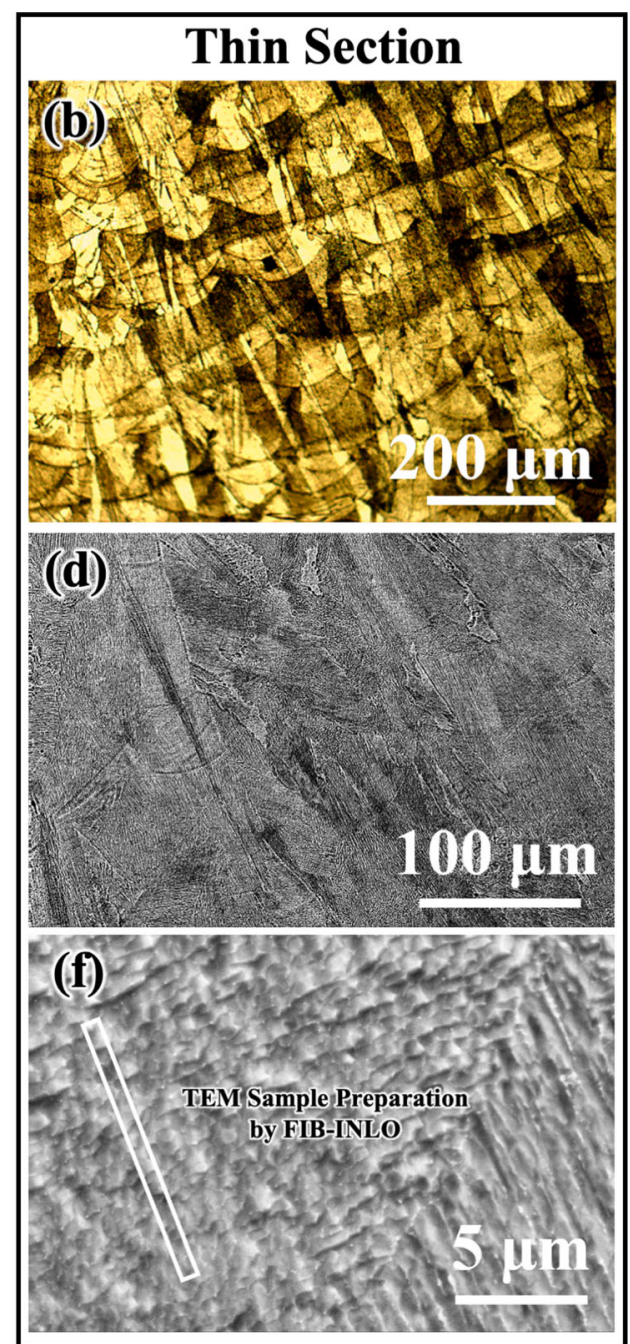

structure and to identify phase constituents found both within the cellular structure and along the intercellular boundaries, FIB-INLO was performed for TEM sample preparation. For both the bulk and thin sections, approximately $10 \mu \mathrm{m}$ by $5 \mu \mathrm{m}$ cross-sectional samples were FIB'ed out perpendicular to the cell walls as indicated in Fig. 2(e) and (f).

Figure 3 presents analytical results from TEM characterization of the as-built IN625 samples. HAADF micrographs, which give atomic number contrast (similar to backscatter in SEM), are shown in Fig. 3(a) and (b). Bright contrast due to the segregation of high atomic number elements was observed along the intercellular boundaries. A few bright-contrast precipitates along the intercellular boundaries, and dark-contrast, spherical precipitates, both in and around the cellular structure were observed in both samples. As depicted by the SAED patterns in Fig. 3(c) and (d), the matrix of both the bulk and thin sections were indexed to be the FCC $\gamma$-phase. Lattice parameters determined from SAED are reported in Table 1. The bright- contrast precipitates were too difficult to identify with SAED, since they were small and located along the intercellular boundaries. Therefore, high resolution TEM (HRTEM) and subsequent FFT process was carried out to yield Fig. 3(e) and (f). These precipitates were identified as the hexagonal closed-packed (HCP) $\mathrm{A}_{2} \mathrm{~B}$ Laves phase, present in both the bulk and thin sections. Lattice parameters determined from the analyses are reported in Table 1, which are similar to that reported in literature. ${ }^{[2,3,34]}$

Compositions determined by TEM-EDXS for the $\gamma$ matrix from the bulk and thin section samples are reported in Table 2. Compared with commercial-production specification, ${ }^{[2]}$ the composition of the $\gamma$-matrix is significantly depleted of $\mathrm{Nb}$ and Mo. Compositions of both the bright and dark precipitates are also reported in Table 3. The bright-contrast precipitates are enriched with $\mathrm{Nb}$ and $\mathrm{Mo}$, while the dark-contrast precipitates contain small amounts of $\mathrm{Al}$ and $\mathrm{O}$. This corresponds well to the TEM analyses that identified the bright-contrast precipitates as Laves phases and suggests that the dark-contrast precipitates are 
Fig. 3 HAADF TEM

micrographs from the (a) bulk and (b) thin sections of the asbuilt IN625 where SAED patterns from the FCC $\gamma$-matrix were obtained for both the (c) the bulk and (d) thin sections. In addition, presence of $\mathrm{A}_{2} \mathrm{~B}$ Laves phase was confirmed by FFT of HRTEM micrographs for both the (c) the bulk and (d) thin sections
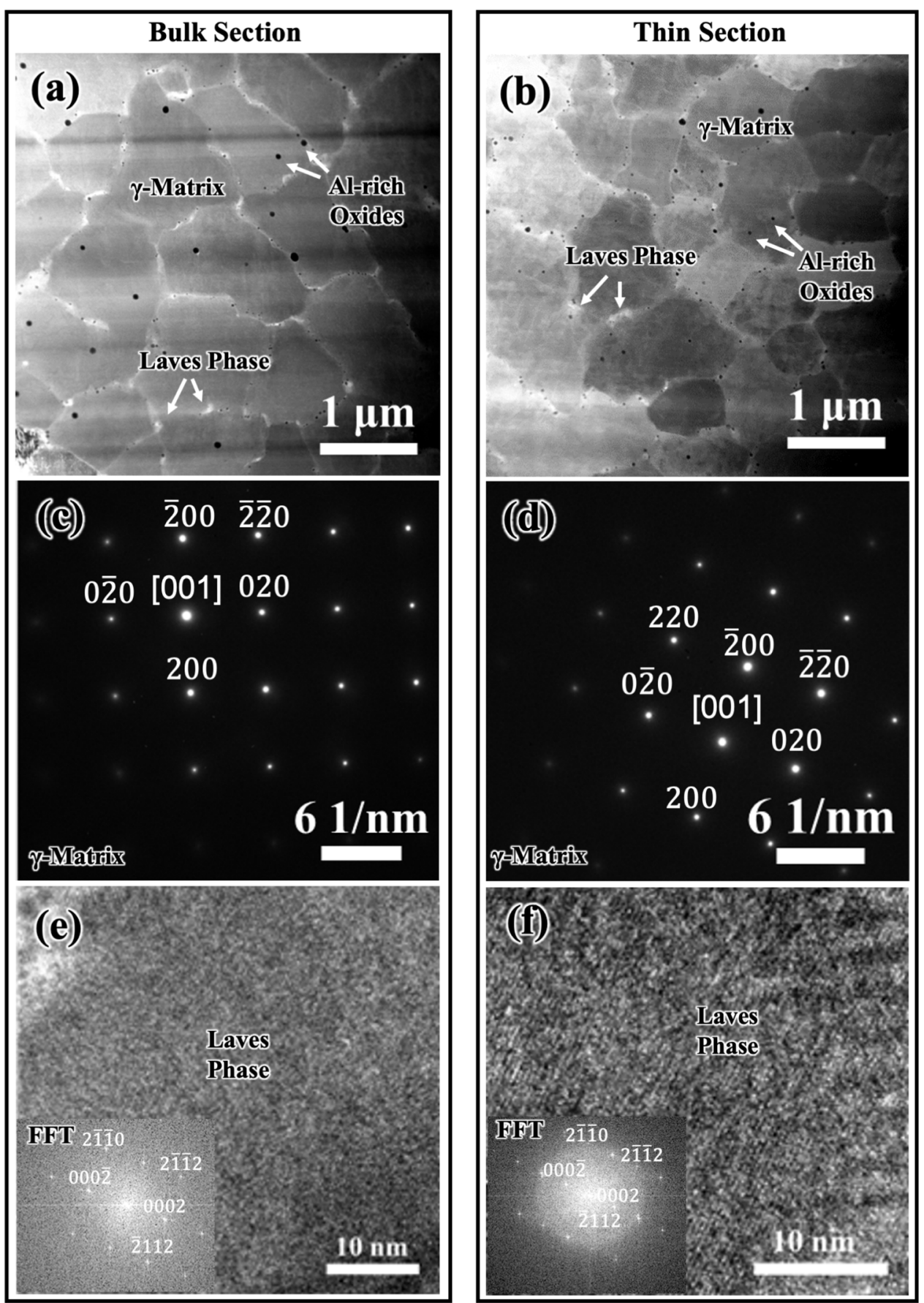

most likely Al-rich oxides. Figure 4 further demonstrates that the intercellular boundaries were indeed enriched in $\mathrm{Nb}$ and Mo by EDXS elemental mapping. Similar subgrain, intercellular boundary segregation with presence of Laves phases has been observed in as-built LPBF IN718 by Zhou et al. ${ }^{[15]}$ In their work, the Laves phases along the intercellular boundaries were also enriched with $\mathrm{Nb}$ and $\mathrm{Mo}$, and, relatively to the matrix, depleted of $\mathrm{Ni}, \mathrm{Cr}$, and $\mathrm{Fe}$. Thus, the Laves phases are most likely (Ni, Cr,
$\mathrm{Fe})_{2}(\mathrm{Nb}, \mathrm{Mo})$ in chemistry. Zhou et al. ${ }^{[15]}$ also reported observing similar Al enriched oxides in LPBF IN718.

\subsection{Microstructure of the Fully Heat Treated (FHT) IN625}

Results from the characterization of the FHT IN625 are presented in Fig. 5, 6, and 7. The optical micrographs in Fig. 5(a) and (b) and the backscatter electron micrographs in Fig. 5(c) and (d) revealed that the melt pool structure has 
Table 1 Lattice parameters determined from selected area electron diffraction for the phase constituents found in the as built and heat treated LPBF IN625

\begin{tabular}{|c|c|c|}
\hline Sample description & Phase constituent & Average lattice parameter, $\AA$ \\
\hline \multicolumn{3}{|l|}{ As built } \\
\hline Bulk Section & FCC $\gamma$-Matrix & $\mathrm{a}=3.61$ \\
\hline Thin section & & $\mathrm{a}=3.63$ \\
\hline Bulk section & $\mathrm{HCP} \mathrm{Fe}_{2} \mathrm{Mo}$ laves phase & $\mathrm{a}=4.23, \mathrm{c}=7.62$ \\
\hline Thin section & & $\mathrm{a}=4.10, \mathrm{c}=7.65$ \\
\hline \multicolumn{3}{|l|}{ Fully heat treated } \\
\hline \multirow[t]{2}{*}{ Bulk section (without cellular structure) } & FCC $\gamma$-Ni solid solution & $\mathrm{a}=3.60$ \\
\hline & $\mathrm{FCC} \mathrm{M}_{6} \mathrm{C}$ & $\mathrm{a}=11.00$ \\
\hline \multirow[t]{2}{*}{ Thin section (grain without "peppery" appearance) } & FCC $\gamma$-Ni solid solution & $\mathrm{a}=3.62$ \\
\hline & $\mathrm{FCC} \mathrm{M}_{6} \mathrm{C}$ & $\mathrm{a}=11.02$ \\
\hline \multirow[t]{2}{*}{ Thin section (grain with "peppery" appearance) } & FCC $\gamma$-Ni solid solution & $\mathrm{a}=3.70$ \\
\hline & $\mathrm{FCC} \mathrm{M}_{6} \mathrm{C}$ & $\mathrm{a}=11.15$ \\
\hline \multicolumn{3}{|l|}{ HIP'ed at alternate temperature $T_{3}$} \\
\hline \multirow[t]{2}{*}{ Thin section } & FCC $\gamma$-matrix & $\mathrm{a}=3.60$ \\
\hline & FCC MC carbide & $\mathrm{a}=4.35$ \\
\hline
\end{tabular}

Table 2 Composition measured by TEM EDXS for the FCC $\gamma$-matrix in the as-built bulk and thin section samples of IN625

\begin{tabular}{lccc}
\hline Element (radiation) & Bulk section, wt.\% & Thin section, wt.\% & Specification, wt.\% ${ }^{[1]}$ \\
\hline $\mathrm{Si}(\mathrm{K})$ & 0.14 & 0.78 & $0.5 \mathrm{max}$ \\
$\mathrm{Cr}(\mathrm{K})$ & 22.74 & 23.23 & $20.0-23.0$ \\
$\mathrm{Fe}(\mathrm{K})$ & 6.53 & 5.58 & $5.0 \mathrm{max}$ \\
$\mathrm{Ni}(\mathrm{K})$ & 67.09 & 67.87 & $58.0 \mathrm{~min}$ \\
$\mathrm{Nb}(\mathrm{L})$ & 0.28 & 0.66 & $3.15-4.15$ \\
$\mathrm{Mo}(\mathrm{L})$ & 2.97 & 1.85 & $8.0-10.0$ \\
$\mathrm{Ta}(\mathrm{M})$ & 0.19 & 0.00 & Trace \\
$\mathrm{Al} / \mathrm{Ti}(\mathrm{K})$ & 0.00 & 0.00 & $0.4-0.8$ max \\
\hline
\end{tabular}

Table 3 Composition measured by TEM EDXS for the precipitates found in the as-built bulk and thin section samples of IN625

\begin{tabular}{lrr}
\hline Element (radiation) & Bright precipitates $\left(\mathrm{Fe}_{2}\right.$ Mo laves phase, wt.\%) & Dark precipitates $\left(\mathrm{Al}_{2} \mathrm{O}_{3}\right.$ oxides, wt.\%) \\
\hline $\mathrm{O}(\mathrm{K})$ & 0.00 & 1.47 \\
$\mathrm{Si}(\mathrm{K})$ & 1.43 & 0.84 \\
$\mathrm{Cr}(\mathrm{K})$ & 20.93 & 24.75 \\
$\mathrm{Fe}(\mathrm{K})$ & 3.05 & 5.35 \\
$\mathrm{Ni}(\mathrm{K})$ & 55.54 & 62.94 \\
$\mathrm{Nb}(\mathrm{L})$ & 9.47 & 1.16 \\
$\mathrm{Mo}(\mathrm{L})$ & 8.13 & 2.28 \\
$\mathrm{Ta}(\mathrm{M})$ & 1.41 & 0.00 \\
$\mathrm{Al}(\mathrm{K})$ & 0.00 & 1.08 \\
\hline
\end{tabular}

disappeared after heat treatment. The grains in the bulk section appeared more equiaxed, with many precipitates dispersed uniformly throughout the microstructure. Moreover, the presence of twins suggested that recrystallization has occurred. Conversely, in the thin section, twins were rare, and the grains did not appear to have recrystallized, because they were still columnar/elongated. Furthermore, many larger, columnar grains contained a "peppery" 

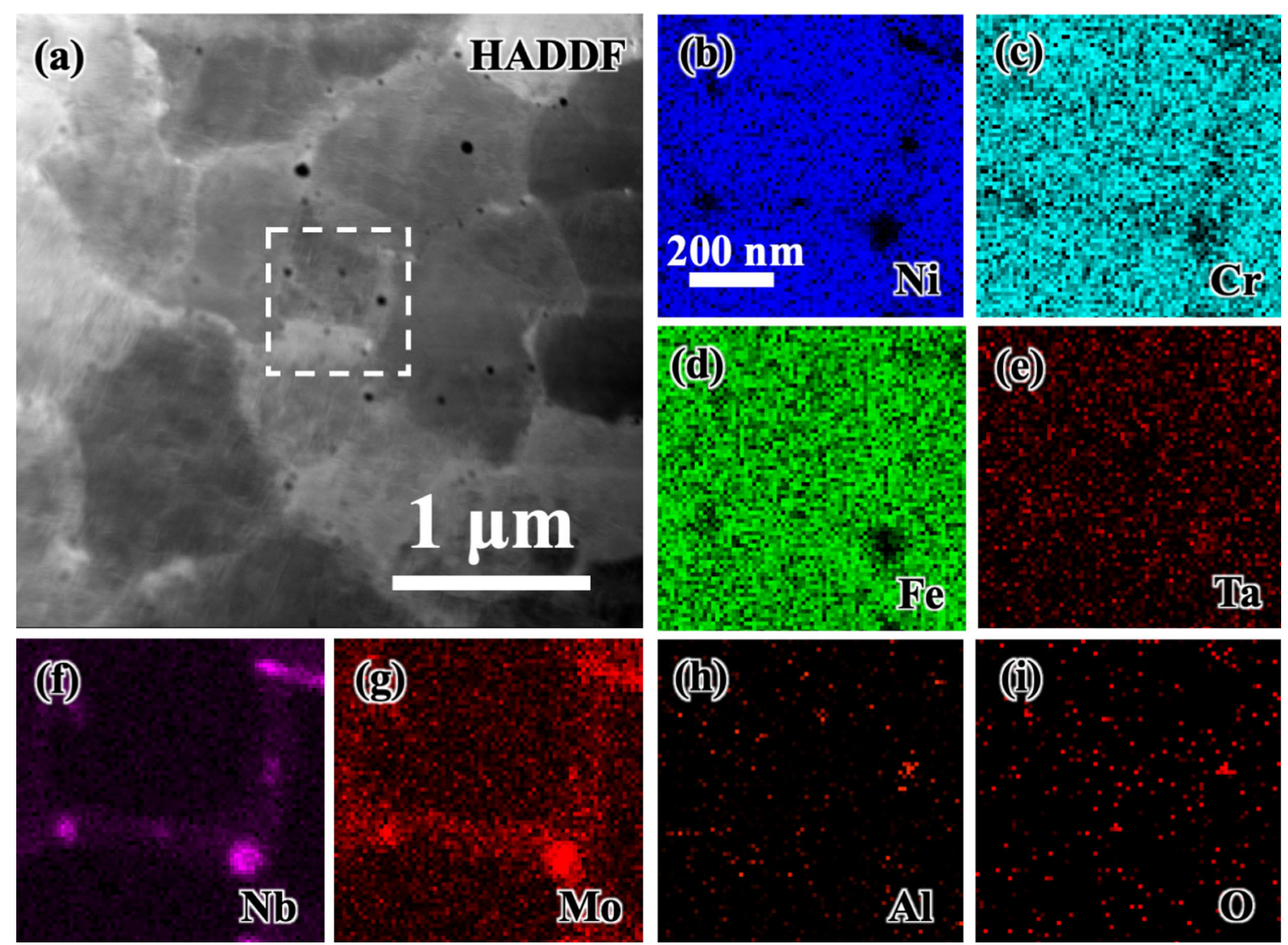

Fig. 4 (a) HAADF micrograph from the as-built IN625 sample with corresponding EDXS elemental mapping for (b) Ni, (c) Cr, (d) Fe, (e) Ta, (f) $\mathrm{Nb},(\mathrm{g}) \mathrm{Mo}$, (h) Al, and (i) $\mathrm{O}$ for the boxed region marked in (a)

Fig. 5 (a, b) Optical micrographs and $(\mathrm{c}, \mathrm{d})$ backscatter electron micrographs from fully heat treated $(\mathrm{a}, \mathrm{c})$ bulk and $(\mathrm{b}, \mathrm{d})$ thin section samples of IN625. The trenches left behind from INLO can be seen in (d)
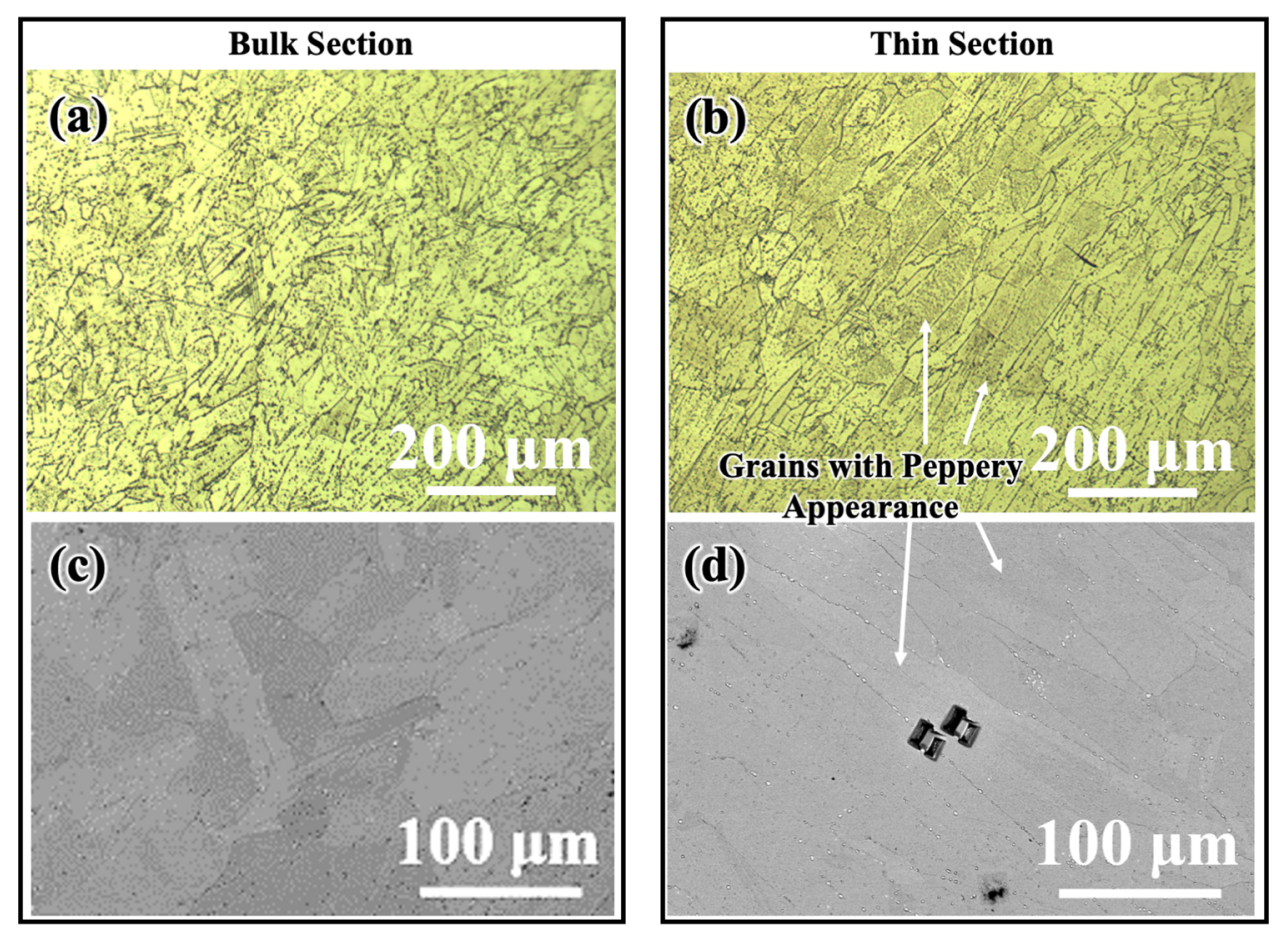

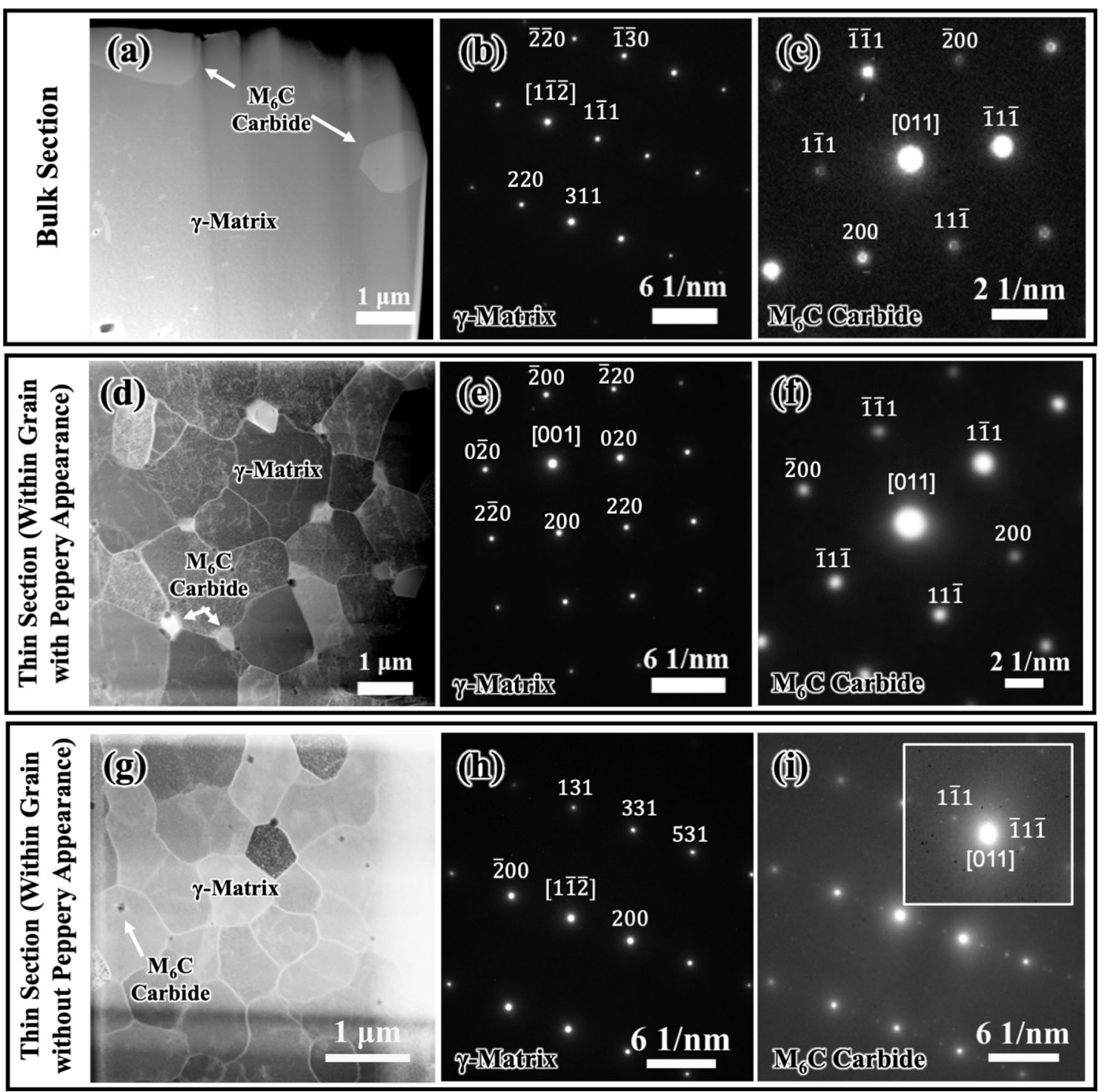

Fig. 6 TEM characterization from the fully heat treated IN625 samples: (a) bulk section samples contained no sub-grain cellularsolidification structure, and consisted of (b) $\gamma$-matrix and (c) $\mathrm{M}_{6} \mathrm{C}$ carbides; (d) thin section sample with peppery appearance retained

texture, presumably due to a high degree of elemental segregation that would yield many undesired secondary phases. To understand this microstructural difference such as the precipitates found in the bulk section and the "peppery" appearance in the thin section, several TEM samples with thin-foil dimension of approximately $10 \mu \mathrm{m}$ by $5 \mu \mathrm{m}$ were prepared by FIB-INLO. Figure 5(d), for example, shows the trenches left behind from sample extractions by FIB-INLO.

Figure 6 presents results from TEM characterization of the FHT IN625 samples: 6(a-c) from the bulk section; 6(df) from a grain with a "peppery" appearance in the thin section; and 6(g-i) from a grain without "peppery" appearance in the thin section. The HAADF micrograph in the sub-grain cellular-solidification structure, and consisted of (b) $\gamma$ matrix and (c) $\mathrm{M}_{6} \mathrm{C}$ carbides; (d) thin section sample without peppery appearance also retained the sub-grain cellular-solidification structure, and consisted of (b) $\gamma$-matrix and (c) $\mathrm{M}_{6} \mathrm{C}$ carbides

Fig. 6(a) shows that, in the bulk section, the sub-grain cellular-solidification structure has been dissolved after the heat treatment, and discrete particles identified as $\mathrm{M}_{6} \mathrm{C}$ carbides, approximately $\sim 1 \mu \mathrm{m}$ in size were observed as presented in Fig. 6(c). Conversely, the HAADF micrographs in Fig. 6(d) and (g) from the thin section samples show that the cellular-solidification structure distinctively persisted even after the heat treatment. Several brightcontrast particles approximately $\sim 1 \mu \mathrm{m}$ in size were observed to decorate the intercellular boundaries from the grains within the thin section sample with a "peppery" appearance. However, these large $\mathrm{M}_{6} \mathrm{C}$ carbides were noticeably smaller and fewer in the thin section sample without a "peppery" appearance. The few dark-contrast 

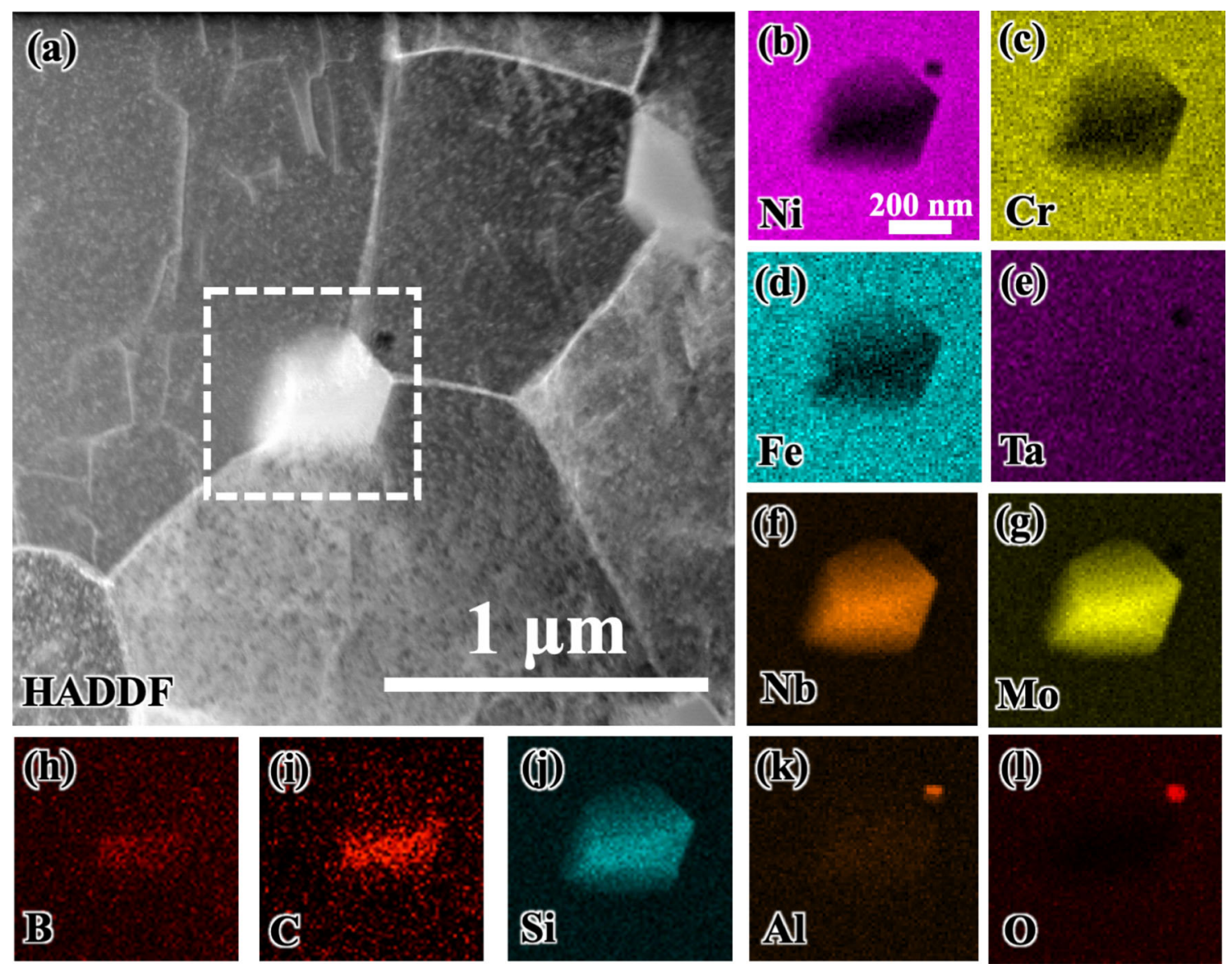

Fig. 7 (a) HAADF micrograph from the fully heat treated IN625 sample containing a carbide precipitate from the thin section of a grain with a peppery appearance. Corresponding EDXS elemental
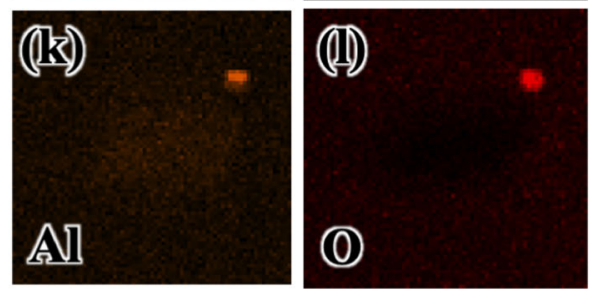

particles observed in all samples are most likely Al-rich oxides previously distinguished from the as-built microstructure.

According to the literature, uniformly distributed oxide inclusions less than $100 \mathrm{~nm}$ in size, as observed in this study, are believed to have negligible influences on mechanical properties. ${ }^{[35]}$ Carbides have been known to both enhance and deteriorate the mechanical properties. ${ }^{[1,2,35,36]}$ Small carbides can help prevent interface sliding to improve strength, fatigue, and creep life. ${ }^{[2,35]}$ Moreover, small carbides located at the grain boundary can act to pin the boundaries, further increasing the strength of the alloy. However, excessively large carbides $(>1 \mu \mathrm{m})$ have been reported to reduce ductility and fatigue life. ${ }^{[2,35]}$

The matrix for all three samples was indexed to be FCC $\gamma$ as shown by the SAED patterns in Fig. 6(b), (e), and (h). Lattice parameters determined based on SAED are reported in Table 1. Compositions determined by EDXS for the FCC $\gamma$-matrix in all three FHT samples are reported in Table 4, and they are similar among all three samples, and closer to the commercial specification. ${ }^{[2]}$ However, the mapping for (b) Ni, (c) Cr, (d) Fe(e) Ta, (f) Nb, (g) Mo, (h) B, (i) C, (j) $\mathrm{Si},(\mathrm{k}) \mathrm{Al}$, and (l) $\mathrm{O}$ taken from marked region in (a)

matrix of a grain without peppery appearance in the thin section was found to be depleted of Mo and Nb. It is likely that the intercellular boundaries are still heavily segregated with $\mathrm{Nb}$ and $\mathrm{Mo}$, and little of each element has dissolved into the matrix. Moreover, this may explain why only a few precipitates were observed, since extensive carbide formation was only observed in a grain with a peppery appearance. SAED patterns from the bright-contrast, FCC $\mathrm{M}_{6} \mathrm{C}$ carbides found in all three samples are presented in Fig. 6(c), (f), and (i). Lattice parameters determined for the $\mathrm{M}_{6} \mathrm{C}$ carbides from the SAED are reported in Table 1 . Composition estimated by EDXS for the $\mathrm{M}_{6} \mathrm{C}$ carbides is reported in Table 5 for each sample. Since the SAED pattern was indexed to be a carbide, the precipitates were checked for C and B. Indeed, both C and B were observed in the EDXS data, but were not considered for quantitative analysis due to inaccuracy of the low atomic number elements. In general, the $\mathrm{M}_{6} \mathrm{C}$ carbides are enriched with $\mathrm{Nb}$, $\mathrm{Mo}, \mathrm{Si}$, and $\mathrm{Al} .{ }^{[35]}$ Correspondingly, the EDXS elemental mapping presented in Fig. 7 confirmed that the $\mathrm{M}_{6} \mathrm{C}$ carbides are enriched in $\mathrm{Nb}, \mathrm{Mo}, \mathrm{B}, \mathrm{C}, \mathrm{Si}$, and $\mathrm{Al}$, while 
Table 4 Composition measured by TEM EDXS for the $\gamma$-matrix found in the fully heat treated bulk and thin sections samples of IN625

\begin{tabular}{lccc}
\hline Element (radiation) & Bulk section, wt.\% & Thin section (grain with a pepper region, wt.\%) & Thin section (grain with no pepper region, wt.\%) \\
\hline $\mathrm{Si}(\mathrm{K})$ & 0.14 & 0.75 & 0.53 \\
$\mathrm{Cr}(\mathrm{K})$ & 21.20 & 22.50 & 25.22 \\
$\mathrm{Fe}(\mathrm{K})$ & 5.52 & 4.84 & 5.65 \\
$\mathrm{Ni}(\mathrm{K})$ & 57.31 & 56.81 & 63.00 \\
$\mathrm{Nb}(\mathrm{L})$ & 4.24 & 3.67 & 1.94 \\
$\mathrm{Mo}(\mathrm{L})$ & 10.87 & 10.87 & 3.63 \\
$\mathrm{Ta}(\mathrm{M})$ & 0.69 & 0.51 & 0.00 \\
$\mathrm{Al} / \mathrm{Ti}$ & 0.00 & 0.00 & 0.00
\end{tabular}

Table 5 Composition measured by TEM EDXS for the $\mathrm{M}_{6} \mathrm{C}$ carbides found in the fully heat-treated bulk and thin sections samples of IN625 Element (radiation) Bulk section, wt.\% Thin section (grain with a pepper region, wt.\%) Thin section (grain with no pepper region, wt.\%)

\begin{tabular}{lrrr}
\hline $\mathrm{Si}(\mathrm{K})$ & 2.52 & 3.03 & 0.60 \\
$\mathrm{Cr}(\mathrm{K})$ & 11.49 & 11.56 & 25.46 \\
$\mathrm{Fe}(\mathrm{K})$ & 1.66 & 2.24 & 5.51 \\
$\mathrm{Ni}(\mathrm{K})$ & 28.13 & 26.63 & 62.53 \\
$\mathrm{Nb}(\mathrm{L})$ & 31.62 & 26.67 & 2.37 \\
$\mathrm{Mo} \mathrm{(L)}$ & 23.33 & 27.08 & 2.97 \\
$\mathrm{Ta} \mathrm{(M)}$ & 1.21 & 2.75 & 0.52 \\
$\mathrm{Al} / \mathrm{Ti}$ & 2.52 & 3.03 & 0.60 \\
\hline
\end{tabular}

depleted of $\mathrm{Ni}, \mathrm{Cr}$, and $\mathrm{Fe}$. Therefore, the chemistry of the $\mathrm{M}_{6} \mathrm{C}$ carbides can be labelled as $(\mathrm{Nb}, \mathrm{Mo}, \mathrm{Si}, \mathrm{Al})_{6}(\mathrm{~B}, \mathrm{C})$. It should also be noted that the $\mathrm{Nb}$ and Mo content in the carbides found within a grain without peppery appearance were depleted in $\mathrm{Nb}$ and Mo, further suggesting that the intercellular boundaries are indeed still heavily enriched with $\mathrm{Nb}$ and Mo.

The microstructure in the as-built sections appeared similar between the bulk and thin section samples, but there was a clear distinction of the sub-grain cellular structure dissolution after the heat treatment. Only the samples from thin overhang sections exhibited columnar grains with a "peppery" appearance under optical microscopy, and it corresponded to the presence of the sub-grain cellular-solidification structure observed by TEM. During the building of the complex component, because of geometrical differences (e.g., overhanging thin section), the heat dissipation rate, which controls the solidification rate, during LPBF processing would be different between the bulk and thin sections. As schematically illustrated in Fig. 1, the thin, overhang section would conduct heat away differently than the bulk section (e.g., rate and path of heat dissipation) - most likely the thin section would have a lower cooling rate than that of the bulk section. Heigel et al. [30] performed a thorough investigation on the differences in melt pool geometry and cooling rate between supported and overhang sections of LPBF processed IN625 component. They noted that the cooling rate was indeed significantly lower in the overhang section than in the supported section. A lower cooling rate would yield a higher degree of micro-segregation since the material would remain at elevated temperature for a longer period. Therefore, to sufficiently dissolve the high degree of microsegregation in the thin section, heat treatment of the thin section would require higher temperatures and/or longer duration than for the bulk section.

Extended exposure to heat in the thin section resulting from a slower cooling rate may also decrease the residual stress, and potentially, lower the dislocation density. It has been shown that AM parts have a large dislocation density, on the order of $<2 * 10^{14}$ dislocations $/ \mathrm{m}^{2}$, ${ }^{[22,37]}$ similar magnitudes found in cold worked metals. ${ }^{[38]}$ A higher magnitude of residual stress and dislocation density should lead to a faster recovery and recrystallization rate. ${ }^{[39]}$ Since there was almost no evidence of recrystallization in the thin section after heat treatment, it is likely that the residual stress magnitude and dislocation density would be lower in the thin section, corresponding to a lower stored energy available for recrystallization. However, further studies are warranted to understand the relationship among LPBF 
process, residual stress, dislocation density and recrystallization in LPBF IN625.

\subsection{Microstructure of FHT IN625 with an Alternate Hot Isostatic Press}

To eliminate the persistent elemental segregation along the sub-grain cellular-solidification boundaries in the thin section, heat treatment was carried out with an alternate HIP cycle using a temperature of $T_{3}$, instead of $T_{2}$. It should be noted that the complete heat treatment, again consisted of stress relief at $\mathrm{T}_{1}$, followed by HIP at $\mathrm{T}_{3}$, and solution annealing at $T_{1}$. The temperature used for the alternative HIP was higher than $T_{2}$, i.e., $T_{3}>T_{1}>T_{2}$. For experimental consistency and repeatability, another IN625 thin section was HIP'ed at $T_{2}$ and examined. Figure 8 shows optical micrographs of samples: 8(a) HIP'ed at $\mathrm{T}_{2}$, and 8(b) HIP'ed at the higher temperature of $\mathrm{T}_{3}$. Consistently, the sample HIP'ed at the lower temperature of $\mathrm{T}_{2}$ revealed columnar, larger grains once again, with an

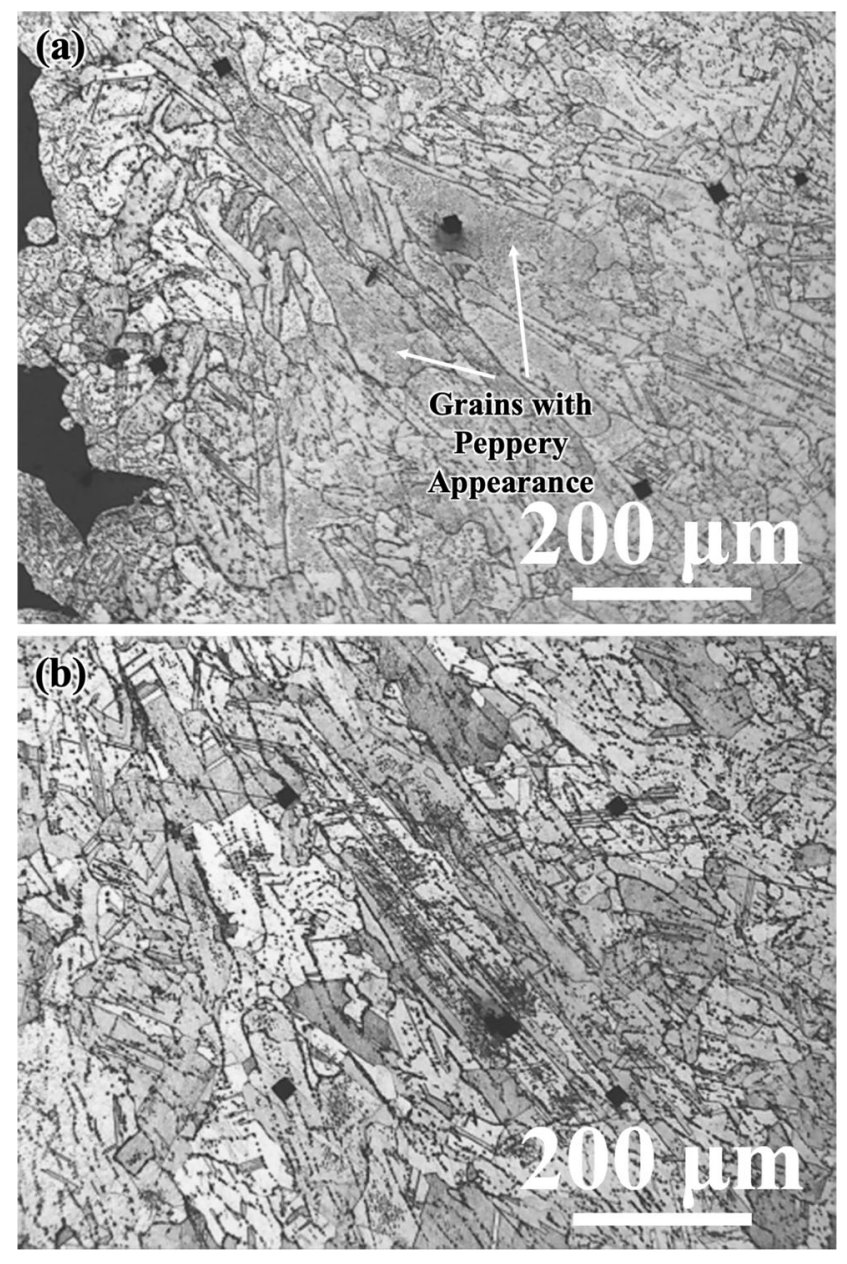

Fig. 8 Optical micrographs from fully heat-treated thin section samples that were HIP'ed at temperature, (a) $T_{2}$ and (b) $T_{3}$ appearance of a "peppery" region. On the other hand, the "peppery" region within the grains disappeared in the sample HIP'ed at the higher, alternate temperature of $\mathrm{T}_{3}$, although only an onset of the recrystallization was observed with a few twins. For consistency, a sample from the bulk section was also HIP'ed at the higher temperature $\mathrm{T}_{3}$, and a complete dissolution of the cellular structure was observed, similar to that shown in Fig. 6 a.

TEM analysis for the sample HIP'ed at the higher, alternate temperature of $T_{3}$ is presented in Fig. 9. The HAADF micrograph in Fig. 9(a) clearly demonstrated that the sub-grain cellular-solidification structure was completely dissolved. Presence of a twin also suggested that recrystallization has indeed occurred. As shown in Fig. 9(b) and (c), the matrix was indexed to be the FCC $\gamma$ phase, while the precipitates were indexed to be FCC MC carbides, and not $\mathrm{M}_{6} \mathrm{C}$. Lattice parameters determined from SAED are reported in Table 1. Composition measured by standardless EDXS analysis is reported in Table 6 for the $\gamma$-matrix and MC carbides. The lattice parameter and composition of the $\gamma$-matrix are similar to those determined from other samples. The MC carbides after the alternate HIP were enriched with $\mathrm{Ti}$, and can be described as ( $\mathrm{Ti}$, $\mathrm{Nb}, \mathrm{Mo}, \mathrm{Ni}, \mathrm{Cr}, \mathrm{Fe}) \mathrm{C}$. Zhou et al. ${ }^{[15]}$ also observed small $(\sim 50 \mathrm{~nm})$ MC carbides in LPBF IN718, enriched in Ti in the as-built microstructure, after direct ageing at 620 and $720{ }^{\circ} \mathrm{C}$ for $8 \mathrm{~h}$ each, and after heat treatment at 980 and $1065^{\circ} \mathrm{C}$.

MC carbides have been observed after casting and LPBF for IN625 in regions with high $\mathrm{Nb}$ segregation, i.e., at the grain boundaries and interdendritic regions.1,2,26,35] Marchese et al. ${ }^{[26]}$ observed small $(10-50 \mathrm{~nm}) \mathrm{MC}$ carbides along the intercellular boundaries in the as-built LPBF IN625. They also reported that a direct ageing at lower temperature $\left(<700{ }^{\circ} \mathrm{C}\right)$ led to the formation of the $\mathrm{M}_{23} \mathrm{C}_{6}$ carbide, while solution annealing at high temperature $\left(1150{ }^{\circ} \mathrm{C}\right)$ resulted in development of the MC carbides. Similarly, Stoudt et al. ${ }^{[20]}$ observed MC carbide formation after solution annealing at $950{ }^{\circ} \mathrm{C}$. Typically, in cast IN625, formation of $\mathrm{M}_{23} \mathrm{C}_{6}$ and $\mathrm{M}_{6} \mathrm{C}$ carbides results from the decomposition of primary $\mathrm{MC}$ carbides, usually at temperatures lower than $1000{ }^{\circ} \mathrm{C}{ }^{[35]}$ In this study, no primary $\mathrm{MC}$ carbides, but only $\mathrm{M}_{6} \mathrm{C}$ carbides were observed in both the as-built bulk and thin sections. This observation suggests that differences in temperature and cooling rates in the two sections were not sufficient to alter the carbide formation during the LPBF. However, there were enough differences to alter the dissolution of subgrain cellular-solidification structure and recrystallization, presumably due to differences in cooling rate. Use of a higher temperature, $\mathrm{T}_{3}$ during the HIP, was sufficient to remove intercellular segregation, dissolve the sub-grain cellular-solidification structure, and avoid the $\mathrm{M}_{6} \mathrm{C}$ carbide 
Fig. 9 (a) HAADF micrograph of the thin section sample HIP'ed at temperature $T_{3}$ with corresponding SAED patterns for the (b) FCC $\gamma$-matrix and (c) FCC MC carbide

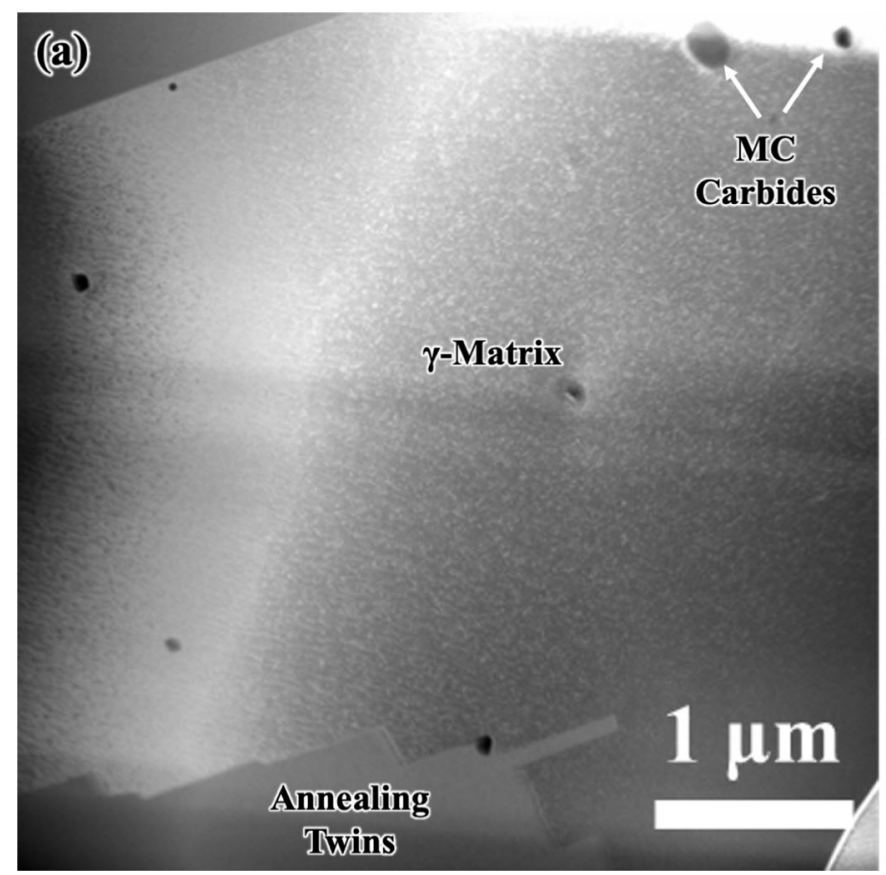

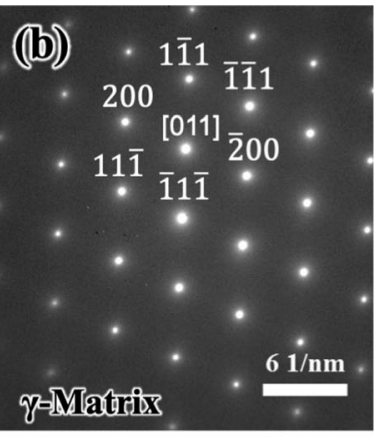

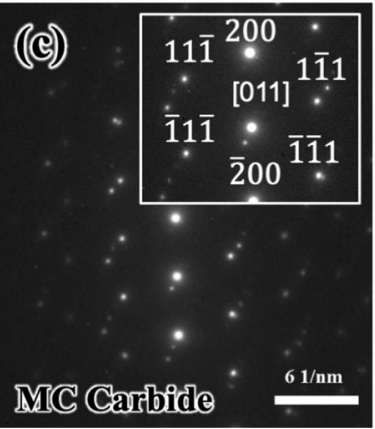

Table 6 Composition measured by EDXS for the $\gamma$-matrix and MC carbide found in the thin section of the sample, HIP'ed at a higher temperature $\mathrm{T}_{3}$

\begin{tabular}{lcc}
\hline Element (radiation) & $\gamma$-matrix, wt.\% & MC carbide, wt.\% \\
\hline Si $(K)$ & 0.17 & 0.00 \\
Ti $(K)$ & 0.00 & 23.07 \\
Cr $(K)$ & 21.12 & 2.09 \\
Fe $(K)$ & 2.11 & 0.41 \\
Ni $(K)$ & 62.88 & 1.03 \\
Nb (K) & 3.89 & 70.30 \\
Mo (K) & 9.80 & 3.07 \\
\hline
\end{tabular}

formation (usually around $900-1000{ }^{\circ} \mathrm{C}$ ) with well-distributed MC carbides. A detailed microstructural development study, as functions of LPBF parameters, sample geometry that changes the heat dissipation, and subsequent heat treatment is warranted to systematically elucidate the dissolution of sub-grain cellular-solidification structure, carbide formation, and recrystallization in IN625.

\section{Summary}

A detailed microstructural examination of IN625 component manufactured by LPBF was performed on samples extracted from locations characterized by two different geometries (denoted as bulk and thin) before (as-built) and after the heat treatment, which consisted of stress-relief,
HIP, and final solution anneal. Findings from this study include:

In the as-built LPBF IN625 alloy component, a subgrain cellular-solidification structure was found with $\mathrm{Nb}$ and Mo segregation along the intercellular boundaries in both the bulk and thin sections. The $\mathrm{A}_{2} \mathrm{~B}$ Laves phase was identified to decorate the intercellular boundaries and a small number of uniformly distributed Al-rich oxide particles were observed.

Both the bulk and thin sections were subjected to heat treatment that consisted of stress-relief, HIP and homogenization. The sub-grain cellular-solidification structure was found to dissolve in the bulk section along with the development of equiaxed grains and twins from recrystallization. However, in the thin, overhang section of the component, the cellular-solidification structure persisted even after heat treatment. Large columnar/elongated grains were found in the thin section, and some of these grains exhibited a "peppery" appearance under optical microscopy, which corresponded to the large degree of intercellular precipitates.

After heat treatment, the undesirable $\mathrm{M}_{6} \mathrm{C}$ carbides were observed in both the bulk and thin sections. This observation suggests that differences in temperature and cooling rates in these two sections were not sufficient to alter the $\mathrm{M}_{6} \mathrm{C}$ formation during the LPBF. In addition, these $\mathrm{M}_{6} \mathrm{C}$ carbides were observed along the sub-grain intercellular boundaries within the grain with "peppery" appearance for the thin section sample.

Use of a higher temperature during HIP portion of the heat treatment enabled a complete dissolution of the sub- 
grain cellular-solidification structure in the thin section along with recrystallization and $\mathrm{MC}$ carbides formation.

With the alternate heat treatment that includes HIP at higher temperature, components with complex geometrical design containing thin, overhang sections have been employed successfully during the RL10 engine testing.

Acknowledgments This research was contracted by and performed under the auspices of Aerojet Rocketdyne by the University of Central Florida. Accordingly, Aerojet Rocketdyne retains authority to reproduce and distribute reprints for Aerojet Rocketdyne purposes notwithstanding any copyright notation herein. Use of the Materials Characterization Facility at UCF is graciously acknowledged.

\section{References}

1. H. Eiselstein and D. Tillack, The Invention and Definition of Alloy 625, Superalloys, 1991, 718(625), p 1-14

2. S. Floreen, G.E. Fuchs, and W.J. Yang, The Metallurgy of Alloy 625, Superalloys, 1994, 718(625), p 13-37

3. F. Cortial, J. Corrieu, and C. Vernot-Loier, Influence of Heat Treatments on Microstructure, Mechanical Properties, and Corrosion Resistance of Weld Alloy 625, Metall. Mater. Trans. A, 1995, 26(5), p 1273-1286

4. H. Eiselstein, Metallurgy of a Columbium-Hardened NickelChromium-Iron Alloy, Advances in the Technology of Stainless Steels and Related Alloysed, ASTM International, West Conshohocken, 1965

5. J. Mittra, S. Banerjee, R. Tewari, and G.K. Dey, Fracture behavior of Alloy 625 with different precipitate microstructures, Mater. Sci. Eng., A, 2013, 574, p 86-93

6. M. Sundararaman, P. Mukhopadhyay, and S. Banerjee, Precipitation of the $\delta$-Ni $3 \mathrm{Nb}$ PHASE in Two Nickel Base Superalloys, Metall. Trans. A, 1988, 19(3), p 453-465

7. E.A. Lass, M.R. Stoudt, M.E. Williams, M.B. Katz, L.E. Levine, T.Q. Phan, T.H. Gnaeupel-Herold, and D.S. Ng, Formation of the $\mathrm{Ni} 3 \mathrm{Nb} \delta$-phase in Stress-Relieved Inconel 625 Produced via Laser Powder-Bed Fusion Additive Manufacturing, Metall. Mater. Trans. A, 2017, 48(11), p 5547-5558

8. D. Herzog, V. Seyda, E. Wycisk, and C. Emmelmann, Additive Manufacturing of Metals, Acta Mater., 2016, 117, p 371-392

9. W. King, A. Anderson, R. Ferencz, N. Hodge, C. Kamath, S. Khairallah, and A. Rubenchik, Laser Powder Bed Fusion Additive Manufacturing of Metals; Physics, Computational, and Materials Challenges, Appl. Phys. Rev., 2015, 2(4), p 041304

10. C. Yap, C. Chua, Z. Dong, Z. Liu, D. Zhang, L. Loh, and S. Sing, Review of Selective Laser Melting: Materials and Applications, Appl. Phys. Rev., 2015, 2(4), p 041101

11. W.J. Sames, F. List, S. Pannala, R.R. Dehoff, and S.S. Babu, The Metallurgy and Processing Science of Metal Additive Manufacturing, Int. Mater. Rev., 2016, 61(5), p 315-360

12. L. Zhou, H. Pan, H. Hyer, S. Park, Y. Bai, B. McWilliams, K. Cho, and Y. Sohn, Microstructure and Tensile Property of a Novel AlZnMgScZr Alloy Additively Manufactured by Gas Atomization and Laser Powder Bed Fusion, Scr. Mater., 2019, 158, p 24-28

13. L.N. Carter, X. Wang, N. Read, R. Khan, M. Aristizabal, K. Essa, and M.M. Attallah, Process Optimisation of Selective Laser Melting Using Energy Density Model for Nickel Based Superalloys, Mater. Sci. Technol., 2016, 32(7), p 657-661
14. J.H. Boswell, D. Clark, W. Li, and M.M. Attallah, Cracking During Thermal Post-Processing of Laser Powder Bed Fabricated CM247LC Ni-Superalloy, Mater. Des., 2019, 174, p 107793

15. L. Zhou, A. Mehta, B. McWilliams, K. Cho, and Y. Sohn, Microstructure, Precipitates and Mechanical Properties of Powder Bed Fused Inconel 718 Before and after Heat Treatment, $J$. Mater. Sci. Technol., 2019, 35(6), p 1153-1164

16. Y.-L. Kuo, S. Horikawa, and K. Kakehi, The Effect of Interdendritic $\delta$ Phase on the Mechanical Properties of Alloy 718 Built up by Additive Manufacturing, Mater. Des., 2017, 116, p 411418

17. P. Kanagarajah, F. Brenne, T. Niendorf, and H. Maier, Inconel 939 Processed by Selective Laser Melting: Effect of Microstructure and Temperature on the Mechanical Properties Under Static and Cyclic Loading, Mater. Sci. Eng. A, 2013, 588, p $188-195$

18. C. Li, R. White, X. Fang, M. Weaver, and Y. Guo, Microstructure Evolution Characteristics of Inconel 625 Alloy from Selective Laser Melting to Heat Treatment, Mater. Sci. Eng. A, 2017, 705, p 20-31

19. S. Li, Q. Wei, Y. Shi, Z. Zhu, and D. Zhang, Microstructure Characteristics of Inconel 625 Superalloy Manufactured by Selective Laser Melting, J. Mater. Sci. Technol., 2015, 31(9), p 946-952

20. M.R. Stoudt, E.A. Lass, D.S. Ng, M.E. Williams, F. Zhang, C.E. Campbell, G. Lindwall, and L.E. Levine, The Influence of Annealing Temperature and Time on the Formation of $\delta$-Phase in Additively-Manufactured Inconel 625, Metall. Mater. Trans. A, 2018, 49(7), p 3028-3037

21. H. Hyer, L. Zhou, S. Park, G. Gottsfritz, G. Benson, B. Tolentino, B. McWilliams, K. Cho, and Y. Sohn, Understanding the Laser Powder Bed Fusion of AlSi10Mg Alloy, Metallogr. Microstruct. Anal., 2020, 9, p 484-502

22. K. Gola, B. Dubiel, I. Kalemba-Rec, Microstructural Changes in Inconel 625 Alloy Fabricated by Laser-Based Powder Bed Fusion Process and Subjected to High-Temperature Annealing. J. Mater. Eng. Perform., 2020, 29, p 1528-1534

23. Special Metals Datasheet Inconel Alloy 625, ed., Special Metals Corporation (2013)

24. G. Lindwall, C. Campbell, E. Lass, F. Zhang, M.R. Stoudt, A.J. Allen, and L.E. Levine, Simulation of TTT Curves for Additively Manufactured Inconel 625, Metall. Mater. Trans. A, 2019, 50(1), p 457-467

25. T. Keller, G. Lindwall, S. Ghosh, L. Ma, B.M. Lane, F. Zhang, U.R. Kattner, E.A. Lass, J.C. Heigel, and Y. Idell, Application of Finite Element, Phase-Field, and CALPHAD-Based Methods to Additive Manufacturing of Ni-Based Superalloys, Acta Mater., 2017, 139, p 244-253

26. G. Marchese, M. Lorusso, S. Parizia, E. Bassini, J.-W. Lee, F. Calignano, D. Manfredi, M. Terner, H.-U. Hong, D. Ugues, M. Lombardi, and S. Biamino, Influence of Heat Treatments on Microstructure Evolution and Mechanical Properties of Inconel 625 Processed by Laser Powder Bed Fusion, Mater. Sci. Eng. A, 2018, 729, p 64-75

27. A. Kreitcberg, V. Brailovski, and S. Turenne, Effect of Heat Treatment and Hot Isostatic Pressing on the Microstructure and Mechanical Properties of Inconel 625 Alloy Processed by Laser Powder Bed Fusion, Mater. Sci. Eng. A, 2017, 689, p 1-10

28. Y.M. Arısoy, L.E. Criales, T. Özel, B. Lane, S. Moylan, and A. Donmez, Influence of Scan Strategy and Process Parameters on Microstructure and Its Optimization in Additively Manufactured Nickel Alloy 625 via Laser Powder Bed Fusion, Int. J. Adv. Manuf. Technol., 2017, 90(5-8), p 1393-1417

29. Z. Gan, Y. Lian, S.E. Lin, K.K. Jones, W.K. Liu, and G.J. Wagner, Benchmark Study of Thermal Behavior, Surface Topography, and Dendritic Microstructure in Selective Laser 
Melting of Inconel 625, Integr. Mater. Manuf. Innov., 2019, 8(2), p 178-193

30. J.C. Heigel, B.M. Lane, and L.E. Levine, In Situ Measurements of Melt-Pool Length and Cooling Rate During 3D Builds of the Metal AM-Bench Artifacts, Integr. Mater. Manuf. Innov., 2020, 9(1), p 31-53

31. M.R. Stoudt, M.E. Williams, L.E. Levine, A. Creuziger, S.A. Young, J.C. Heigel, B.M. Lane, and T.Q. Phan, Location-Specific Microstructure Characterization Within IN625 Additive Manufacturing Benchmark Test Artifacts, Integr. Mater. Manuf. Innov., 2020, 9(1), p 54-69

32. M.R. Stoudt, M.E. Williams, L.E. Levine, A. Creuziger, S.A. Young, J.C. Heigel, B.M. Lane, T.Q. Phan, Location-Specific Microstructure Characterization Within In625 Additive Manufacturing Benchmark Test Artifacts. Integr. Mater. Manuf. Innov., 2020, 9, p 54-69

33. F. Zhang, L.E. Levine, A.J. Allen, S.W. Young, M.E. Williams, M.R. Stoudt, K.-W. Moon, J.C. Heigel, and J. Ilavsky, Phase Fraction and Evolution of Additively Manufactured (AM) 15-5
Stainless Steel and Inconel 625 AM-Bench Artifacts, Integr. Mater. Manuf. Innov., 2019, 8(3), p 362-377

34. ICSD - Inorganic Crystal Structure Database, ed., FIZ Karlsruhe (2019)

35. C.T. Sims, N.S. Stoloff, and W.C. Hagel, Superalloys II, Wiley, New York, 1987

36. S. Singh Handa, Precipitation of Carbides in a Ni-Based Superalloy, ed. (2014)

37. A. Hadadzadeh, C. Baxter, B.S. Amirkhiz, and M. Mohammadi, Strengthening Mechanisms in Direct Metal Laser Sintered AlSi10Mg: Comparison Between Virgin and Recycled Powders, Addit. Manuf., 2018, 23, p 108-120

38. R. Abbaschian and R.E. Reed-Hill, Physical Metallurgy Principles, Cengage Learning, Boston, 2008

39. F.C. Campbell, Elements of Metallurgy and Engineering Alloys, ASM International, West Conshohocken, 2008

Publisher's Note Springer Nature remains neutral with regard to jurisdictional claims in published maps and institutional affiliations. 